\title{
A Review on Energy Efficient Clustering Protocols of Heterogeneous Wireless Sensor Network
}

\author{
Santosh Vishnu Purkar (Research Scholar) ${ }^{1}$, Dr. R.S.Deshpande (Research Guide) ${ }^{2}$ \\ ${ }^{1,2}$ Department of Electronics and Telecommunication, Affiliated to Savitribai Phule Pune University \\ M.C.O.E.R.C Nashik, Eklahare (M.S), India \\ ${ }^{1}$ santosh.purkar@rediffmail.com \\ S.C.S.C.O.E.Ahmednagar, Nepti (M.S) \\ India \\ ${ }^{2}$ raj.deshpande@yahoo.co.in
}

\begin{abstract}
Today is the era of information technology, collect the information and use it for required application with technology support. Sensor nodes operating remotely are the popular approach for today's researcher for collecting real time information. But, facing difficulty due to constraints of energy resource for long life monitoring. So there is high need to have energy efficient communication scheme for the betterment of sensor network communication. Clustering protocol is the best option in designing routing protocol for Wireless Sensor Network (WSN). Though we have option of heterogeneity, Clustering approach enhances the energy efficiency of WSN by systematically sharing the load and hence prolongs the lifetime of the network. Most of the researchers achieve energy efficient approach in WSN, by adding different level high energy nodes and use clustering approach to prolong the lifetime of WSN. There are lots of efforts put in reality by researchers for the development of energy efficient schemes with WSN. This paper explored the contribution of different clustering scheme reported in published literature in the three sections as Clustering algorithm basic and its different attributes, suggested Cluster head selection criteria, literature survey and the identified gaps found in published material. The main aim of this paper is to present basic considered in designing clustering algorithm and metrics available for validation.
\end{abstract}

Keyword- Clustering basics, Node degree, Performance measures, Query

\section{INTRODUCTION}

The main aim of WSN is to be a witness and become the reporter for the events of the physical world [44]. Over the last two decade WSNs Popularity has been increased tremendously in several applications like scientific, industrial and social domain to explore events $[4,45]$. All these applications use static placement of sensor nodes. For example in Scientific domain by putting nodes at appropriate places at top of mountain, at Glaciers field, at suitable point in city and at water dam bottom side[8,45], it is possible to predict the accurate forecast [43]. In industrial domain we can use sensor nodes in electrical machine for monitoring the status of armature, and other parts of electrical motor [38, 43]. Sensor nodes can be used, in power plant monitoring. In approximately all cases, sensor nodes have to be dependent on their limited powered battery and processing power resource, and after deployment are usually unattended from sensing regions [52]. In social domain WSN can be used for environmental monitoring, some of the times in wildfires monitoring [40,50]. In Military applications sensor network is used as in target tracking, battlefield surveillance, and container monitoring are some of the dynamic node applications from WSN [8, 15, 20,36,60]. Sensing the events and routing the recorded valuable data for longer life is found to be extremely important and challenging.

The above said applications demands energy efficient schemes for WSN [23], so that available energy of WSN is use systematically and network can serve for longer life. Solution for above point is, data traffic at run time must be evenly distributed over available sensor node. Network reliability must be maintain during event monitoring. For the entire above requirement, clustering is the best solution [3, 5, 44]. In clustering heterogeneous WSN (HWSN) sensing work is almost handle by small energy capable node and data from all sensor is collected and forwarded towards sink is done by high energy nodes, other than their regular work (named as cluster head in clustered scenario) [49,52]. With clustering approach in real time scenario different parameters are explored like stability period, throughput, propagation delay and reliable data delivery. Hence 
lifetime of the network get prolong. Currently about $50 \%$ of the researcher are interested in energy efficient method to prolong the life time of wireless sensor network and $50 \%$ of those are working on different schemes like aggregation, security and different sink arrangement etc. [47]. In latest reported public material shows that clustering is an efficient scheme for hierarchical network routing, balancing the load of traffic, enhancing the stability period and hence prolonging the network lifetime $[1,16,60,47]$. Clustering is a scheme through which sensor network is divided into groups with central controller for each usually called as Cluster head $(\mathrm{CH})$ with responsibility as to be update and live all the time and maintain intra-connectivity as well as inter connectivity with sink or base station $[42,46]$. Clustering reduces the overall energy consumption between networks with the expense of small communication effort.

There are basically two approach of clustering as probabilistic, non-probabilistic. Non probabilistic approach further support for bio-inspired schemes of clustering. Clustering schemes can also be grouped as centralized and distributed approach $[28,45,62]$. This paper is an attempt from our side to highlight the recent development in clustering HWSN based on different criteria as algorithmic strategy, metrics considered, software used other than merits, demerits and number of energy level of nodes. The rest of the paper is organized as basics of HWSN and objectives of HWSN, clustering basics and objectives of clustering, cluster head selection criteria, performance measures of clustering WSN, Data transfer approach in clustered WSN, observations from our side in the form of findings from reviewed literature and summary followed by literature survey and finally there is conclusion.

\section{CLUSTERING HETEROGENOUS WIRELESS SENSOR NETWORK}

We are presented some basics for clustering Heterogenous WSN, brief about heterogeneous WSN and then clustering are explained with this section.

\section{A. Heterogeneous WSN (HWSN)}

WSN's are of two kinds homogeneous and heterogeneous [22]. In homogeneous WSN, all nodes have same capabilities as processing, energy level (in the form of battery) battery source and link bandwidth etc. But, in reality once sensor network start for event monitoring and updating it no longer being a homogeneous network. As energy level available with sensor nodes is not same. Hence it becomes heterogeneous WSN. Hence, Heterogeneous WSN is the suitable sensor network for real time event monitoring [46]. As the WSN which consist different capabilities like processing, energy level and link bandwidth etc. But, node with different energy level is the best option for heterogeneous WSN. As different capabilities like processing and link bandwidth demand energy backup [1, 23, 29, 42, 48, 53]. Objectives of adding heterogeneous nodes in WSN are listed as follows.

1) Increase the data transmission speed: Due to high capability of processing, energy level and link bandwidth improves data manipulation speed and with high energy level, data can be transmitted at long distance than simple sensor node or normal node. With high link bandwidth no waiting period or data with high rate transfer is achieved $[1,23]$.

2) Enhance the lifetime and network throughput: As high energy node available which compensate for high processing power and high link bandwidth reduce the burden of packet transfer. With high energy node stability of the network get enhance, on the cost of high initial energy in the network [1,23].

3) Enhance the reliability of data communication: As with high energy level, high link bandwidth and with high processing capability makes manipulation more precise and with less effort data can be transferred to base station or sink $[1,23]$.

4) Enhance coverage within network: With high energy node, connectivity in the network get elongated. It also support for high scalability in the network [1].

\section{B. Clustering basics}

"To group the same capability or same functionality related physical elements", and assign or arrange for the specific task, for the required outcome is termed as cluster [2, 28]. Some of the main objectives of clustering scheme are listed as follows.

1) Systematic Load sharing among the nodes is possible: As there is $\mathrm{CH}$ selection or election, then TDMA frame from the $\mathrm{CH}$ towards sensor nodes. Every node send collected information in allotted time slot $[1,2,45]$. 
2) Node failure can be identified: With acknowledgment received from cluster member $\mathrm{CM}$ to $\mathrm{CH}$ after advertisement. TDMA frame is formed only with replied nodes not with all the available. At the start of every cluster cycle this process is repeated $[1,2]$.

3) Reduce the intra message in the network: Without clustering every node have to participate in completion of data transfer to sink. On the contrary with single hop or multi-hop communication need to adapt for data transfer. Also chain based approach is possible for without clustered environment for data transmission but, if any intermediate node of chain failure results in loss of valuable data $[1,2]$.

\section{Clustering process}

WSN can be reactive or proactive, but the clustering process having some stages $[12,13,18]$. These stages are common in all kind of clustering scheme, as selection of cluster head, cluster setup phase and steady state phase. First there is the cluster head $(\mathrm{CH})$, which is one of the node from the available network nodes. Which can be fixed or selected based on some strategy, which is totally controlled by algorithm working over the network. Selected cluster head intimated by sink or by the sensor nodes working in the network. Once $\mathrm{CH}$ is selected or elected then it intimates to all other nodes can be called as cluster members, which is in coverage of communication radius. Intimation is all the way through advertising its identifiers like its id, energy level available, its closeness with base station or all other cluster member and cluster member reply to $\mathrm{CH}$ by updating appropriate information in routing table such as receiving signal strength, hop count, relative distance with $\mathrm{CH}$ etc. This is cluster setup phase. With the reception of reply, $\mathrm{CH}$ design time schedule as TDMA frame (Time division multiple access frame) as per the number of cluster member and send it over coverage span. CSMA/CA is the collision avoidance scheme most probably used. Here after all the members send their respective collected data to $\mathrm{CH}$ only in pre-decided time slot. The time span after issuing TDMA frame to all node reply (all member reply) on their respective time slot, is called cluster cycle. This completes the steady state phase of cluster process $[1,2]$.

There are some of the cluster head selection criteria's, which are explored as follows.

\section{D. $\mathrm{CH}$ selection criteria}

Clustered network mainly have three entities as cluster head (CH), sensor node ( $\mathrm{SN}$ ) and base station (BS). Main control entity is $\mathrm{CH}$, for selecting $\mathrm{CH}$ we listed different attributes from the reviewed literature is as follows.

1) Initial energy: In this scheme the nodes which have higher energy (battery source) is selected as $\mathrm{CH}$. For example advance nodes or super nodes can be $\mathrm{CH}[1,20,23]$.

2) Residual energy: Nodes with higher remaining energy compared with all other nodes from the coverage zone is selected as $\mathrm{CH}[1,11,16,23,25,31,34]$.

3) Random or probabilistic: Any node can be $\mathrm{CH}$ in this criteria without considering its capability, position and its relative distance etc. Such as random number generated by sensor nodes and whose number is less as compared to other is selected as $\mathrm{CH}[6,18,38,49,50]$.

4) Distance from sink: The node whose distance from the all other cluster member is small with respect to sink node can be selected as $\mathrm{CH}$. Some of the time other criteria is also added for $\mathrm{CH}$ selection as node having greater connectivity with all others and distance is also less compared with others is selected as $\mathrm{CH}[10,14,15$, 20].

5) Energy consumption rate: The node whose energy depletion rate is lower compared with other nodes from the coverage zone is selected as $\mathrm{CH}$. Some of the time other parameter is also added with energy required for current round by the selected $\mathrm{CH}[16,21,22,41]$.

6) Ratio of parameters: Ratio of residual energy to average energy of the network, ratio of initial energy to residual energy and distance to $\mathrm{CM}$ with respect distance sink are the different options for selecting $\mathrm{CH}$ in current round [1,8,10,11,14-16,20,23-25,31,35,39,42,44].

7) Node degree: Node with strongest connectivity with all the cluster member is selected as CH. Node who receive maximum level Receive Signal Strength Indicator (RSSI), so that packet can be received from cluster member is $\mathrm{CH}$ for the round [11].

8) Hybrid approach: Cluster head selection criteria in which more than one parameter considered for $\mathrm{CH}$ selection. Means node with higher energy available and small distance with sink, initial energy and remaining node energy with average energy of the network. There can be criteria as epoch period with remaining energy, Node with low hop count towards sink and better connectivity selected as CH [19,27,29,30-33,36,37,43,44,46$48,52]$. 
Clustering performance can be evaluated with reference to some of the listed performance measures of clustered WSN

\section{E. Performance measures of Clustering WSN}

Mostly considered performance parameter by the researchers is as follows.

1) Stability period: The time interval between start of network (very first message triggered in the network) to very first node death is termed as stability period. Because it is the interval over which all the nodes from the network are working against energy exertion without sacrifice $[1,6,7,15,18,19,22,24,25,27,29,32,34,47,56,64]$.

2) Lifetime period: It is the second important matric parameter found in almost all the published literature for energy efficient sensor network, other than stability period. The time span after the start of network to death of last available node from the network, is termed as lifetime of WSN [1,6,7,10,15,16,19,22-24,27$29,32,33,38,39,43,47]$.

3) Throughput of the network: Number of messages transacted over the network towards base station per cluster cycle or cluster round is termed as throughput $[1,11,13,17,18,21-24,26,27,29,30-35,37,41,42,45,46-$ $48,57,58,61,64]$.

4) Number of cluster heads per round: Number of clusters formed over a cluster cycle is recorded in the form of number of $\mathrm{CH}$ per round. This value must be optimum [10, 14, 15-17, 23, 36, 39, 41, 59, 61, 64].

5) Energy consumption per round: Energy spent by the cluster and hence WSN per round is termed as energy consumption per round. This factor gives us an information of available energy over the network and tentative lifetime of the network possible. If energy required for one round is known then approximate lifetime of network can be calculated $[6,7,11-15,22,25,26,30-36,38,39,42,45,46,48,52,59,63]$.

6) Number of alive or dead node: Number of nodes alive or dead per cluster cycle is one of the important parameter of performance measures. This parameter gives us idea of tentative death of all nodes and hence lifetime can be predicted [1,6,10-14,17,18,21-23,24,26,29-38,39,42,46,47, 50,56,58,59,61,63,64].

\section{F. Data transfer approach in clustered WSN}

Data collection from WSN is possible through three different ways, with reference to base station. In heterogeneous network there can be possibility of mix types of nodes instead of same sensing parameter. By the help of query, time and threshold base approach it is possible to collect the information for required sensing event.

1) Query based: In query based approach the query of administrator is placed from BS over the network towards $\mathrm{CH}$. $\mathrm{CH}$ in response forwards the said query for searching information over a network. The sensor node send the collected information to $\mathrm{CH}$ as a response. Only matched data will be send by all respective $\mathrm{CH}$ to BS. But, while collected data is being send by sensor nodes at the same time there energy level information is also conveyed to respective $\mathrm{CH}[12,13,57]$.

2) Time threshold: In this time frame sent by selected cluster head to member and collect the data from those entire member. Transfer the aggregated data after collection followed by $\mathrm{CH}$ selection. In this scheme all $\mathrm{CH}$ are tightly synchronized with each other [13, 16, 34].

3) Threshold based: In case of threshold value based scheme information collected by sensor nodes is monitored an update till the threshold is reached. Once threshold is achieved then the collected data will be sent to $\mathrm{CH}$. Same platform followed by $\mathrm{CH}$, it collect the data from all the cluster member till the threshold of its own is reached from aggregated value before sending towards BS $[12,18]$.

\section{LITERATURE SURVEY}

According to research effort taken by researcher for the development of best possible routing protocol through clustering scheme based on probability strategy. But, they have their target application or network architecture. On the other side there can be different options possible, one of the option other than probability strategy is combining different parameter for clustering or through non-probabilistic approach reducing energy consumption in the WSN. Which indirectly enhance the lifetime of network.

\section{A. Clustering schemes of Homogeneous WSN}

Towards this work many researcher contribute and propose energy efficient scheme for homogeneous and for heterogeneous WSN [23]. Low Energy Adaptive Clustering Hierarchy protocol (LEACH) proposed in $[6,7,8]$ is the protocol more suitable in the environment over which role of $\mathrm{CH}$ is rotated after each cluster cycle. So, that load balancing and hence energy efficiency in WSN can be achieved. CH selection is based 
on random number, in this every sensor node generates random number and if the generated number is less than the threshold given in [6] is elected as $\mathrm{CH}$ for current round. $\mathrm{CH}$ send advertise message to sensor nodes of his coverage. Cluster member reply to advertised message by sending acknowledgement. After receiving acknowledgement $\mathrm{CH}$ prepare a schedule of TDMA frame and publish over the network (Cluster section of his control) every node send the collected data within their allotted time slot. Time span between transfer of TDMA frame from $\mathrm{CH}$ to again data collected frame to $\mathrm{CH}$ and aggregated data to base station is termed as Cluster cycle or cluster round. LEACH protocol is suitable for homogeneous WSN not for heterogeneous WSN. As LEACH select the CH based on random number without considering the available energy or relative distance etc. hence selected $\mathrm{CH}$ is less faithful than expected. To resolve the issue of LEACH, A hybrid energy efficient distributed (HEED) clustering approach for ad hoc sensor networks (HEED) protocol from [10] which undertake residual energy of the node for the selection of $\mathrm{CH}$ and relative distance with respect to BS. This protocol us slight faithful CH than LEACH, but having less emphasis on node connectivity and available energy within the network or energy consumption rate of selected node. PEGASIS protocol proposed in [9] is one of the different direction for energy efficient WSN, in the form of chain based data communication to BS. With this study many of the researchers are trying to encompass different parameter for the best choice of $\mathrm{CH}$ selection and with multihop scheme [51].

\section{B. Clustering Schemes of Heterogeneous WSN}

As in real time WSN, no network found to be homogeneous for long time. Heterogeneous WSN (HWSN) is the popular network architecture for real time sensing environment. Researchers of Heterogeneous WSN protocol are motivated from the basics of homogeneous WSN protocol like $[6,7,9,10]$, so that energy consumption per cluster cycle is to be reduced as much possible. To enhance the energy efficiency and indirectly enhance the stability period of WSN, hence prolong the lifetime of WSN. By rotating the role of cluster head and threshold will be set for the selection of $\mathrm{CH}$, on the same base as LEACH. Very first heterogeneous WSN protocol proposed in [17] is with two type nodes as normal and advanced node. A CH selection criterion for this protocol is based on remaining energy with nodes and not on the network energy. It means selection of $\mathrm{CH}$ not taken into account global information of the network. This protocol introduces high energy node, hence stability of the network get enhanced and it prolong the lifetime of WSN. Demerits of this scheme is identified as there is always high energy node get selected as $\mathrm{CH}$, hence there is always punishment to advance node. Researchers contribute towards this approach for better stability and better remaining energy and hence to prolong the lifetime of the network in the form of [18, 24, 25]. Enhanced Distributed Energy Efficient Clustering (EDEEC) protocol mentioned in [26] is three level node heterogeneous WSN, in this added node termed as super node. Main aim of this scheme is to increase the heterogeneity and improve stability period, hence lifetime of the network by using the base of [24] or indirectly with the base of [6]. CH selection follows the base of probability with the ratio of remaining energy to average energy of the network. Controlling the epoch period also contribute for enhancing stability period and lifetime of the network in [29]. Some of the other detailed contribution from the researchers for different schemes is organized as follows in Table I. Presents comparison details of contribution for different algorithms proposed by the researchers. Table I mainly focused on Methodology used for algorithm in the form of summary, Design approach of clustering (DA), Importance of protocol (IP), Design matrices used for protocol (DM), merits (M) and demerits (dm) followed by heterogeneity level of nodes (LN) and the tools (TL) mentioned if any used by researchers. 
TABLE I

Comparison table of proposed algorithms

\begin{tabular}{|l|l|l|l|l|l|l|l|l|}
\hline $\begin{array}{l}\text { Sr. } \\
\text { no. }\end{array}$ & $\begin{array}{l}\text { Ref. } \\
\text { no. }\end{array}$ & IP & DA & DM & M & Dm & LN & TL \\
\hline 1 & {$[55]$} & $\begin{array}{l}\text { Cluster head selection } \\
\text { based on routing path to } \\
\text { prolong the network life }\end{array}$ & $\begin{array}{l}\text { Bio-inspired, } \\
\text { Hybrid approach } \\
\text { (A-star Algorithm) }\end{array}$ & $\begin{array}{l}\text { Network life time, } \\
\text { residual energy }\end{array}$ & $\begin{array}{l}\text { Suitable cluster head } \\
\text { selection, enhanced } \\
\text { life time }\end{array}$ & $\begin{array}{l}\text { Intra-cluster and Inter- } \\
\text { cluster message are } \\
\text { increased. Hence latency, } \\
\text { routing table also } \\
\text { increased. }\end{array}$ & 1 & - \\
\hline
\end{tabular}

Summary: This is a novel approach of cluster head selection to enhance life time and longevity of cluster with the consideration of week node count and total distance value for cluster head selection. Routing table include residual energy, is consider for synthesized path to transfer data packet.

\begin{tabular}{|l|l|l|l|l|l|l|l|l|}
\hline 2 & {$[56]$} & $\begin{array}{l}\text { Optimal no.of cluster } \\
\text { head for round and } \\
\text { enhance stability and } \\
\text { lifetime }\end{array}$ & $\begin{array}{l}\text { Random approach } \\
\text { (Semi- } \\
\text { Centralized) }\end{array}$ & $\begin{array}{l}\text { Stability period, } \\
\text { sensing period }\end{array}$ & $\begin{array}{l}\text { High stability, each } \\
\text { round balance energy } \\
\text { utilization }\end{array}$ & $\begin{array}{l}\text { Intra-cluster message, } \\
\text { more Processing load }\end{array}$ & 2 & - \\
\hline
\end{tabular}

Summary: It follows the architecture of Mechanism of LEACH, But with slight change for selection of cluster head this algorithm considers the death toll and the residual energy of all the member and intimate it to BS. Then decision is taken on minimum value from t or k. Hence improve the stability period of network.

\begin{tabular}{|l|l|l|l|l|l|l|l}
\hline 3 & {$[57]$} & Energy efficient routing & $\begin{array}{l}\text { Hybrid random } \\
\text { approach }\end{array}$ & $\begin{array}{l}\text { Better packet delivery } \\
\text { ratio, } \\
\text { energy consumption, } \\
\text { E to E delay/round }\end{array}$ & $\begin{array}{l}\text { Average energy } \\
\text { tilization is less, } \\
\text { improving reliability } \\
\text { of data forwarding, } \\
\text { improve packet } \\
\text { delivery ratio. }\end{array}$ & $\begin{array}{l}\text { Other node may have } \\
\text { valuable data, latency } \\
\text { improved, scalability in } \\
\text { Heterogeneous WSN not } \\
\text { consider }\end{array}$ & 1 \\
\hline
\end{tabular}

Summary: This algorithm works on the principle of LEACH with slight addition as by using residual energy available for routing path. CH selection based on spatial density so that energy consumption is minimum. Concentration degree of SN's and their residual energy for optimal cluster head election can work for election Weight.

\begin{tabular}{|l|l|l|l|l|l|l|l|}
\hline 4 & {$[58]$} & $\begin{array}{l}\text { Better clustering and } \\
\text { reduce Energy } \\
\text { consumption }\end{array}$ & $\begin{array}{l}\text { Probabilistic } \\
\text { approach and } \\
\text { centralized scheme }\end{array}$ & $\begin{array}{l}\text { No.of alive } \\
\text { nodes/round, dead } \\
\text { nodes/round, packet } \\
\text { delivery ration, no.of } \\
\text { cluster/round }\end{array}$ & $\begin{array}{l}\text { Transmission load of } \\
\text { other nodes is } \\
\text { reduced. No initial } \\
\text { energy drainage in } \\
\text { scheme. }\end{array}$ & $\begin{array}{l}\text { Control overhead effect is } \\
\text { nullify, initial energy } \\
\text { drainage for ON/OFF } \\
\text { switching }\end{array}$ & 2 \\
\hline
\end{tabular}

Summary: In order acquire better clustering, we partition the network in four quadrants to achieve better coverage, optimum position of $\mathrm{CH}$ also defined. More over transmission load of other sending nodes is also reduced. In conventional leach cluster are arbitrary in size and some of the cluster member are away from the head. Selection of cluster is based on RSSI received of advertisement. And CH inform schedule to sensor node.

\begin{tabular}{|c|c|c|c|c|c|c|c|c|}
\hline 5 & [28] & $\begin{array}{l}\text { EDDEEC: } \\
\text { (Three node model ) } \\
\text { Cluster head selection } \\
\text { probability and hence } \\
\text { Enhance life time }\end{array}$ & $\begin{array}{l}\text { Non-probabilistic } \\
\text { approach }\end{array}$ & $\begin{array}{l}\text { Stability, lifetime, } \\
\text { packet delivery ratio }\end{array}$ & $\begin{array}{l}\text { Dynamic selection of } \\
\mathrm{CH}\end{array}$ & $\begin{array}{l}\text { Non-balanced clustering, } \\
\text { re-election increased } \\
\text { overhead }\end{array}$ & 3 & MATLAB \\
\hline \multicolumn{9}{|c|}{$\begin{array}{l}\text { Summary: It is a three level node energy approach and Cluster head selection is based on probability, also on residual energy available, and average energy of the network } \\
\text { This scheme uses the concept of Tabs for cluster head selection. Hence give more optimal number of clusters to be formed to provide enhanced stability and life time. }\end{array}$} \\
\hline 6 & [59] & $\begin{array}{l}\text { To reduce the intra- } \\
\text { cluster energy and better } \\
\text { coverage from } \mathrm{CH}\end{array}$ & $\begin{array}{l}\text { Non-probabilistic } \\
\text { approach }\end{array}$ & $\begin{array}{l}\text { Stability, residual } \\
\text { energy/round (life } \\
\text { time) }\end{array}$ & $\begin{array}{l}\text { Balance Energy } \\
\text { consumption and } \\
\text { prolong the survival } \\
\text { time of the network. }\end{array}$ & $\begin{array}{l}\text { Less importance is given } \\
\text { to Intra-cluster, inter- } \\
\text { cluster messages. This } \\
\text { impose more processing } \\
\text { load, scalability increase } \\
\text { energy consumption }\end{array}$ & 1 & OMNET++ \\
\hline
\end{tabular}


Summary: To enhance stability and life time, energy utilization in cluster working must be managed systematically. In this scheme author focused on stable data transfer and cluster formation with the consideration of node degree, relative distance and residual energy and optimal routing predictive path for energy saving. Hence extend the life of network

\begin{tabular}{|l|l|l|l|l|l|l|l|}
\hline 7 & {$[60]$} & $\begin{array}{l}\text { To reduce } \\
\text { communication traffic on } \\
\text { BS }\end{array}$ & $\begin{array}{l}\text { Probabilistic } \\
\text { approach }\end{array}$ & $\begin{array}{l}\text { Packet delivery and } \\
\text { life time }\end{array}$ & $\begin{array}{l}\text { Avoids data collision } \\
\text { and fast message } \\
\text { delivery, hence } \\
\text { prolong the life time }\end{array}$ & $\begin{array}{l}\text { Transmission of power } \\
\text { value and link correlation } \\
\text { (factor) coefficient } \\
\text { increase the power } \\
\text { dissipation }\end{array}$ & 2 \\
\hline
\end{tabular}

Summary: In this paper author focused on bottleneck zone at BS. To overcome this network coding with coefficient is used and link correlation is used for best possible cluster head. Single hop communication is found to be used in entire network. $\mathrm{CH}$ to BS communication assumed to be multi-hop so network coding is used. Hence this scheme overcome the occurrence of collision, redundant data which affect the lifetime of network.

\begin{tabular}{|l|l|l|l|l|l|l|l|l|}
\hline 8 & {$[29]$} & $\begin{array}{l}\text { To enhance stability and } \\
\text { improve the life time of } \\
\text { the network }\end{array}$ & $\begin{array}{l}\text { Non-probabilistic } \\
\text { approach }\end{array}$ & $\begin{array}{l}\text { Residual energy, } \\
\text { packet delivery ratio } \\
\text { and Lifetime }\end{array}$ & $\begin{array}{l}\text { More energy } \\
\text { efficient, hence } \\
\text { extend the stability } \\
\text { period and lifetime }\end{array}$ & $\begin{array}{l}\text { Intra-cluster messages } \\
\text { impose more Processing } \\
\text { load }\end{array}$ & $\begin{array}{l}\text { MATLAB } \\
\text { latime }\end{array}$ &
\end{tabular}

Summary: BEENESH choose different epoch for different node with respect to their remaining energy. With the mechanism of these kind not only efficiently reduce the energy consumption of the network, but also balance the load on the network. Hence extend the stability period and prolong the lifetime of the network.

\begin{tabular}{|l|l|l|l|l|l|l|l|l|}
\hline 9 & {$[52]$} & $\begin{array}{l}\text { To reduce } \\
\text { communication energy in } \\
\text { the network }\end{array}$ & $\begin{array}{l}\text { Random } \\
\text { probabilistic }\end{array}$ & $\begin{array}{l}\text { Residual energy and } \\
\text { life time }\end{array}$ & $\begin{array}{l}\text { High stability and } \\
\text { balance energy } \\
\text { utilization }\end{array}$ & $\begin{array}{l}\text { Intra and inter-cluster } \\
\text { messages are higher }\end{array}$ & $\begin{array}{l}\text { NETBEANS } \\
\text { IDE 7.0 }\end{array}$ \\
\hline
\end{tabular}

Summary: Firefly and Simulated annealing is an hybrid approach for cluster set up and communication is set in which BS computes no.of cluster head based o residual energy (generally $\sim 5 \%$ ) and update this to all nodes. Then in the cluster formation TDMA schedule is published from head along with residual energy. At the end of each $5 \%$ ) ne is sent to BS for next round decisions. Inside cluster relative distance is consider for chaining and hop distance also. Hence it results better utilization of cluster.

\begin{tabular}{|l|l|l|l|l|l|l|l|l|}
\hline 10 & {$[17]$} & $\begin{array}{l}\text { To prolong the stability } \\
\text { and prolong lifetime }\end{array}$ & $\begin{array}{l}\text { Probabilistic } \\
\text { approach }\end{array}$ & Stability and life time & $\begin{array}{l}\text { Reduce energy } \\
\text { consumption, more } \\
\text { chance to generate } \\
\text { optimum CH, more } \\
\text { stabilize protocol }\end{array}$ & $\begin{array}{l}\text { Advance nodes get } \\
\text { punished all the way }\end{array}$ & 2 & MATLAB \\
\hline
\end{tabular}

Summary: SEP (Stable Election Protocol) assumes that in real-life network behave after certain round as heterogenite. This protocol offer higher priority to Initial energy for cluster head selection (i.e. advanced nodes) instead of global energy of the network. Hence it gives the more stable network by reducing the energy consumption in the form of electing advance nodes as $\mathrm{CH}$. CH election probabilities are weighted by the initial energy of a node relative to other nodes from the network.

\begin{tabular}{|c|c|c|c|c|c|c|c|c|}
\hline 11 & [24] & $\begin{array}{l}\text { To reduce energy } \\
\text { consumption and prolong } \\
\text { the lifetime of network }\end{array}$ & $\begin{array}{l}\text { Probabilistic } \\
\text { Approach }\end{array}$ & $\begin{array}{l}\text { Stability and life } \\
\text { time, no. of alive } \\
\text { nodes/ round and } \\
\text { throughput }\end{array}$ & $\begin{array}{l}\text { Avoid the global } \\
\text { knowledge of energy } \\
\text { from the network at } \\
\text { every election round. } \\
\text { Performs better in } \\
\text { multi-level HWSN }\end{array}$ & $\begin{array}{l}\text { In this protocol penalty is } \\
\text { always for advanced } \\
\text { nodes, in the condition } \\
\text { when their energy } \\
\text { deplete and in the range of } \\
\text { the normal nodes. }\end{array}$ & 2 & MATLAB \\
\hline
\end{tabular}

Summary: DEEC is a distributed energy efficient clustering algorithm for heterogeneous WSN. In this cluster heads are selected based on probability using the ratio between residual energy of each node and the average energy of the network. So the node with higher residual energy has the more chance to become $\mathrm{CH}$. With the use of varying epoch strategy, distribute the load over the network. Hence prolong the lifetime specially the stability period as compared to SEP and LEACH.

\begin{tabular}{|l|l|l|l|l|l|l|l|l|}
\hline \multicolumn{2}{|c|}{ epoch strategy, distribute the load over the network. Hence prolong the lifetime specially the stability period as compared to SEP and LEACH. } \\
\hline 12 & {$[25]$} & $\begin{array}{l}\text { To balance the energy } \\
\text { consumption inside the } \\
\text { network by selecting CH } \\
\text { over all the network }\end{array}$ & $\begin{array}{l}\text { Probabilistic } \\
\text { Approach }\end{array}$ & $\begin{array}{l}\text { Stability, residual } \\
\text { energy/round, no.of } \\
\text { alive nodes/round }\end{array}$ & $\begin{array}{l}\text { DDEEC is } \\
\text { advantageous than } \\
\text { DEEC in terms of } \\
\text { stability period. It is } \\
\text { due to hybridization } \\
\text { of DEEC and the }\end{array}$ & $\begin{array}{l}\text { Still there is penalty for } \\
\text { advanced nodes, cluster } \\
\text { heads consume more } \\
\text { energy }\end{array}$ & 2 & MATLAB \\
\hline
\end{tabular}


balance selection of

Summary: Developed Distributed Energy-Efficient Clustering (DDEEC) algorithm select the CH based on residual energy. DDEEC adopts the base of DEEC, to select the cluster heads. After $\mathrm{CH}$ selection procedure and round completion, when advanced node become normal node at one point selection of advance and normal node is of equal possibility and hence life time and stability is enhance.

\begin{tabular}{|l|l|l|l|l|l|l|l|l|}
\hline 13 & {$[35]$} & $\begin{array}{l}\text { To increase the stability } \\
\text { of the network by } \\
\text { enhancing energy } \\
\text { efficiency }\end{array}$ & $\begin{array}{l}\text { Probabilistic } \\
\text { Approach }\end{array}$ & $\begin{array}{l}\text { Remaining energy, } \\
\text { throughput and no.of } \\
\text { alive nodes/ round }\end{array}$ & $\begin{array}{l}\text { High assurance for } \\
\text { node having higher } \\
\text { energy become CH }\end{array}$ & $\begin{array}{l}\text { Need to calculate average } \\
\text { energy of the network for } \\
\text { CH selection, which } \\
\text { consume more energy }\end{array}$ & $\begin{array}{l}>3 \\
\text { MATLAB }\end{array}$ & \\
\hline
\end{tabular}

Sumary: This threshold distributed energy efficient clustering (TDEEC) algorithm modifies the scheme of cluster head selection as with normal procedure of LEACH. TDEEC also use the basis as DEEC, ratio of residual energy to average energy and with the value of optimum no.of cluster heads required and compromise between this is elected for further work. Hence prolong the lifetime of network.

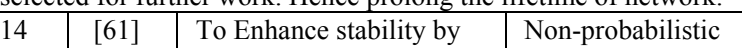
\begin{tabular}{l|l} 
reducing control & approach
\end{tabular}

Instability period, packet delivery/ round, network lifetime and stability

\section{Better and reliable} communication, more stable network Less importance given to
control messages, increase the load over a network,

which required high

processing energy

Summary: In this algorithm BS is responsible for CH selection (based on residual energy, average energy and relative distance between nodes and BS).In this nodes contributed for their respective region information communication. This protocol is validate only with selected protocol.

\begin{tabular}{|l|l|l|l|l|l}
\hline 62] & $\begin{array}{l}\text { To select best location of } \\
\text { CH for improving energy } \\
\text { efficiency }\end{array}$ & Random approach & $\begin{array}{l}\text { No.of clusters and } \\
\text { energy consumption/ } \\
\text { round }\end{array}$ & $\begin{array}{l}\text { It select best location } \\
\text { of CH, non-uniform } \\
\text { cluster formation }\end{array}$
\end{tabular}

\section{It adapts centralized}

mechanism for

management and network

initialization message

have less importance

Summary: This scheme select best possible $\mathrm{CH}$ such that energy consumption get reduced. $\mathrm{CH}$ to BS communication is direct. In case of multiple cluster there is formation of shortest path towards sink and joined to form chain, with the help of single cluster head in the center of cluster algorithm. This scheme consider the boundary condition and density of nodes available in the cluster zone.

\begin{tabular}{|l|l|l|l|l|l|l|l|l|}
\hline 16 & {$[63]$} & $\begin{array}{l}\text { To enhance the lifetime } \\
\text { of sensor network by } \\
\text { reducing energy } \\
\text { consumption }\end{array}$ & $\begin{array}{l}\text { Non-probabilistic, } \\
\text { Hybrid approach }\end{array}$ & $\begin{array}{l}\text { Lifetime (energy } \\
\text { consumption and } \\
\text { time) }\end{array}$ & $\begin{array}{l}\text { It gives best cluster, } \\
\text { reduce intra cluster } \\
\text { energy }\end{array}$ & $\begin{array}{l}\text { Intra-cluster messages are } \\
\text { high }\end{array}$ & 1 & NS-2 \\
\hline
\end{tabular}

Summary: Proposed protocol minimize the possibility first dead nodes and the energy consumption, hence extend the network lifetime. In this, each node in order to calculate the node weight sends a message to BS. For CH selection the proposed protocol uses a hybrid scheme of residual energy, distance between nodes and BS, Weightnode. It means cluster head selected must dissipate minimum energy with mechanism of cluster radius, which reduce network load. The node which has high Pch value than neighbour's get elected as $\mathrm{CH}$. CH send only meaningful information from the collected information.

\begin{tabular}{|l|l|l|l|l|l|l|l|l|}
\hline 17 & {$[64]$} & $\begin{array}{l}\text { To design Energy } \\
\text { efficient scheme and take } \\
\text { full advantage of } \\
\text { heterogeneity }\end{array}$ & Non-probabilistic & $\begin{array}{l}\text { Lifetime, stability, } \\
\text { no.of CH over round } \\
\text { and throughput }\end{array}$ & $\begin{array}{l}\text { Balanced clustering } \\
\text { scheme and obtain } \\
\text { optimum number of } \\
\text { CH to enhance } \\
\text { energy efficiency of } \\
\text { the network }\end{array}$ & $\begin{array}{l}\text { Extra control messages or } \\
\text { overhead }\end{array}$ & 2 & MATLAB \\
\hline
\end{tabular}

clustering.CH selection is again on the basis of residual energy. Cluster formation is based on DEEC strategy and the distance parameter between CH and cluster member. 


\begin{tabular}{|c|c|c|c|c|c|c|c|c|}
\hline 18 & {$[65]$} & $\begin{array}{l}\text { Reducing the energy } \\
\text { consumption and prolong } \\
\text { the lifetime of the } \\
\text { network }\end{array}$ & Non-probabilistic & $\begin{array}{l}\text { Lifetime, energy } \\
\text { consumption, data } \\
\text { packet delivery }\end{array}$ & $\begin{array}{l}\text { Avoid energy } \\
\text { consumption of } \\
\text { hierarchical cluster } \\
\text { by collecting } \\
\text { information in } \\
\text { advance }\end{array}$ & $\begin{array}{l}\text { Level-2 CH Node may } \\
\text { have burden, and deplete } \\
\text { energy at fast rate, Extra } \\
\text { control messages or } \\
\text { overhead }\end{array}$ & 1 & MATLAB \\
\hline \multicolumn{9}{|c|}{$\begin{array}{l}\text { Summary: Double Cluster Based -LEACH propose a CH selection based on residual energy of node, distance from node to base station and neighbour nodes, Node energy } \\
\text { parameter is main factor, Node density for CH selection, Level one for fusion and send it to level two for forwarding to sink. }\end{array}$} \\
\hline 19 & {$[77]$} & $\begin{array}{l}\text { Energy efficient scheme, } \\
\text { distribute load and heavy } \\
\text { data traffic and energy } \\
\text { consumption evenly }\end{array}$ & Non-probabilistic & $\begin{array}{l}\text { Lifetime, average } \\
\text { delay, maximum } \\
\text { transmission distance } \\
\text { and data redundancy, } \\
\text { energy consumption }\end{array}$ & $\begin{array}{l}\text { Balanced clustering, } \\
\text { avoid redundant data, } \\
\text { reduce the } \\
\text { communication } \\
\text { energy }\end{array}$ & $\begin{array}{l}\text { Greater number of internal } \\
\text { control heads consume } \\
\text { more energy }\end{array}$ & 1 & NCTUNs 6.0 \\
\hline
\end{tabular}

Summary: ANCF (Active node cluster formation),Active node sensing algorithm, Active node routing algorithm: is responsible for appointing CH near Sink and event, Hello packet and distance calculation, Active node selection for $\mathrm{CH}$ following parameter up-keeping energy, distance to the neighbour's, Density, Maximum distance,

Angle. And also CH selection follow probability rule, Multihop routing spanning tree algorithm.

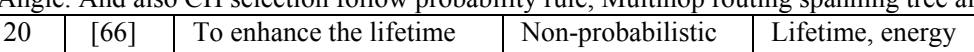

\begin{tabular}{|l|l|l|l|}
\hline of heterogeneous network & $\begin{array}{l}\text { consumption, data } \\
\text { packet delivery }\end{array}$ & $\begin{array}{l}\text { selection and epoch } \\
\text { is modified for } \\
\text { balance energy } \\
\text { efficient clustering, } \\
\text { hence results in } \\
\text { increase lifetime }\end{array}$ & no.of control overheads \\
\hline
\end{tabular}

Summary: It use the basis of DEEC, Node with high energy becomes CH more times than normal nodes. CH is selected based on residual energy. Epoch is modified by the (Energy for round divide by Average energy of the network). This enhance the lifetime than DEEC.

\begin{tabular}{|c|c|l|l|l|l|l|l|l|}
\hline 21 & {$[76]$} & $\begin{array}{l}\text { To design and develop } \\
\text { energy efficient protocol } \\
\text { to create distributed } \\
\text { clusters }\end{array}$ & Non-probabilistic & $\begin{array}{l}\text { Average residual } \\
\text { energy, stability and } \\
\text { Lifetime over network }\end{array}$ & $\begin{array}{l}\text { Distribution of } \\
\text { cluster head is } \\
\text { uniform }\end{array}$ & $\begin{array}{l}\text { Need update at the end of } \\
\text { each round }\end{array}$ & $\begin{array}{l}\text { event-driven } \\
\text { simulator } \\
\text { written in } \\
\text { Java }\end{array}$ \\
\hline
\end{tabular}

Summary: $\mathrm{CH}$ are selected based on residual energy, their distance to other $\mathrm{SN}$ and residual energy of other $\mathrm{SN}$ and $\mathrm{CH}$ close to each other. $\mathrm{CH}$ are Distributed over the network properly such that minimum distance between each other is maintained, so reduce the inter cluster messages. Reduce the communication distance between sensor nodes and BS through $\mathrm{CH}$. This MDBECHAN assure that $\mathrm{CHs}$ are not concentrated at particular zone.

\begin{tabular}{|l|l|l|l|l|l|l|l|}
\hline 22 & {$[68]$} & $\begin{array}{l}\text { To reduce energy } \\
\text { consumption of SN to } \\
\text { communicate with CH }\end{array}$ & Non-probabilistic & $\begin{array}{l}\text { Lifetime, energy } \\
\text { consumption, data } \\
\text { packet delivery and } \\
\text { energy consumed Vs } \\
\text { data packet received at } \\
\text { BS }\end{array}$ & $\begin{array}{l}\text { Avoid CH at } \\
\text { boundary side, } \\
\text { reduce the energy } \\
\text { consumption in the } \\
\text { network }\end{array}$ & $\begin{array}{l}\text { Less chance that every } \\
\text { time CH is found at the } \\
\text { central position other than } \\
\text { first round }\end{array}$ & 1 \\
MATLAB \\
Summary: CH are selected based on residual energy and it is to be at the central position of cluster . The node with minimum value of energy will be TCH for next round and \\
the node with highest RE is CH for next round, also have the provisioning of sleep period. BS is at the outside the network.
\end{tabular}

Summary: This paper focused on different position selection for $\mathrm{CH}$ (Normally heterogenite nodes), as random worst and best position. Random position does not guarantee for reduce energy consumption for data communication in WSN. Worst position is at the border of network, which enhance energy dissipation in the network. So, best 
position is at the center of cluster or at the network. Center position of $\mathrm{CH}$ gives better performance measures than other two positions.

\begin{tabular}{|c|c|c|c|c|c|c|c|c|}
\hline 24 & [70] & $\begin{array}{l}\text { This approach } \\
\text { ameliorates the network } \\
\text { lifespan and minimizes } \\
\text { the energy consumption } \\
\text { of sensor node }\end{array}$ & Non-probabilistic & $\begin{array}{l}\text { Lifetime and total } \\
\text { system energy Vs } \\
\text { Round }\end{array}$ & $\begin{array}{l}\text { Multihop } \\
\text { communication in } \\
\text { clustered routing to } \\
\text { prolong the lifetime }\end{array}$ & $\begin{array}{l}\text { CH selection is based on } \\
\text { random number }\end{array}$ & 1 & MATLAB \\
\hline \multicolumn{9}{|c|}{$\begin{array}{l}\text { Summary: In this approach, network use the minimum transmission energy algorithm to form a cluster with shortest path between nodes down to CH. Multiho } \\
\text { communication between CM to CH is possible. This scheme selects CH based on LEACH strategy. }\end{array}$} \\
\hline 25 & [73] & $\begin{array}{l}\text { Shortest path finding with } \\
\text { energy management }\end{array}$ & $\begin{array}{l}\text { Probabilistic } \\
\text { (Dynamic source } \\
\text { routing) }\end{array}$ & $\begin{array}{l}\text { Lifetime, Remaining } \\
\text { energy and throughput }\end{array}$ & $\begin{array}{l}\text { Multihop } \\
\text { communication to } \\
\text { prolong the usage of } \\
\text { available energy }\end{array}$ & $\begin{array}{l}\text { Calculation and energy } \\
\text { consumption and traffic } \\
\text { overload increase on node } \\
\text { death }\end{array}$ & 1 & NS2 \\
\hline
\end{tabular}

Summary: Source nodes send packet like flooding and with the acceptance of reply from target. Find shortest path towards BS. Check energy level continuously. The route which have higher energy level, is selected as best routing path for communication.

\begin{tabular}{|l|l|l|l|l|l|l|l|}
\hline 26 & {$[72]$} & $\begin{array}{l}\text { Forming a cluster based } \\
\text { on connectivity and } \\
\text { energy level such that } \\
\text { maximum node degree is } \\
\text { achieved and prolong the } \\
\text { lifetime }\end{array}$ & Non-probabilistic & $\begin{array}{l}\text { Lifetime, total } \\
\text { remaining energy, } \\
\text { total number of CH } \\
\text { Vs maximum hops } \\
\text { and lifetime Vs hop } \\
\text { count, lifetime Vs } \\
\text { number of nodes }\end{array}$ & $\begin{array}{l}\text { Due to unequal } \\
\text { clustering there is } \\
\text { enhanced lifetime of } \\
\text { network }\end{array}$ & $\begin{array}{l}\text { This scheme consume } \\
\text { more energy. If any node } \\
\text { dead then there must be } \\
\text { provision of every time } \\
\text { connectivity and energy } \\
\text { level calculations }\end{array}$ & 1 \\
\hline
\end{tabular}

Summary: Connectivity aware and energy information is also added, Maximum connectivity less number of CH. This paper is based on revised version of Kachirski et al. with power connectivity index, this scheme carry power level information other than connectivity index.

\begin{tabular}{|l|l|l|l|l|l|l|l|}
\hline 27 & {$[74]$} & $\begin{array}{l}\text { Selecting best possible } \\
\text { cluster head by the } \\
\text { addition of heterogeneity } \\
\text { nodes. Hence it enhances } \\
\text { the lifetime and } \\
\text { throughput }\end{array}$ & $\begin{array}{l}\text { Non-probabilistic } \\
\text { (Fuzzy logic) }\end{array}$ & $\begin{array}{l}\text { Lifetime, energy total } \\
\text { energy consumption } \\
\text { and throughput, } \\
\text { throughput Vs no.of } \\
\text { sensors, traffic load } \\
\text { Vs sensor nodes and } \\
\text { aggregate delay Vs } \\
\text { no.of nodes }\end{array}$ & $\begin{array}{l}\text { High energy nodes } \\
\text { with density and } \\
\text { distance is the best } \\
\text { strategy for CH } \\
\text { selection. }\end{array}$ & $\begin{array}{l}\text { Calculations from crisp } \\
\text { number to values are } \\
\text { higher due to three } \\
\text { attribute }\end{array}$ & \\
& & & & & \\
\end{tabular}

Summary: CH Selection is based on Residual energy, Node density and Distance to the CH and BS (BS is at the center) with Fuzzy Logic. This scheme input the parameter to fuzzy logic as power, Node density and distance, system generate 27 different combination for best possible $\mathrm{CH}$ selection. Better $\mathrm{CH}$ selection but internal processing is high

\begin{tabular}{|l|l|l|l|l|l|l|l|l|}
\hline 28 & {$[67]$} & $\begin{array}{l}\text { Identify the congested } \\
\text { node path }\end{array}$ & $\begin{array}{l}\text { Probabilistic } \\
\text { (Avoid Congestion } \\
\text { in path) }\end{array}$ & Lifetime & $\begin{array}{l}\text { Lifetime of the } \\
\text { network is prolonged } \\
\text { with the strategy of } \\
\text { best energy path }\end{array}$ & $\begin{array}{l}\text { In this no assurance of CH } \\
\text { is at the center of cluster }\end{array}$ & 1 & NS2 \\
\hline
\end{tabular}

Summary: This protocol is designed for multihop network. Selection of $\mathrm{CH}$ is based on energy associated to transfer information towards BS, available residual energy and node location of node. This scheme use minimum energy path for transferring data packet to BS. 


\section{FINDINGS FROM REVIEWED LITERATURE}

As selecting the $\mathrm{CH}$ at center offers best connectivity in the network, but this scheme have less assurance that $\mathrm{CH}$ is always at the center of cluster. Sending routing schedule over a network with available residual energy and decision based on the same is taken for $\mathrm{CH}$ selection. But, this is time consuming and energy consuming process. Such messaging also increases internal messages over a network. A euclidean distance criterion is less faithful than, selecting $\mathrm{CH}$ based on energy available. Every time for new round initiation messages transacted over the network are proportional to number of parameter and number of calculations with number of nodes available in the network. Most of the literature assumes that internal messages processing energy is negligible. Assuming $\mathrm{CH}$ statically and centrally controlled approach of clustering offers less reliable cluster scheme. Most of the researcher used random deployment for sensor node placement; this is one of the causes for less stable network than uniformly deployed network.

\section{SUMMARY OF REVIEWED LITERATURE}

It is identified that, precise the selection of $\mathrm{CH}$ better the clustering connectivity or node degree and hence better the performance measures of clustered WSN. Hence at the end of this study, we found that SEP and its variants consider the residual energy as main parameter for probability ratio calculation. Which contribute all the way for better stability, hence enhances the throughput of the SEP and its variants. On the other side DEEC and its variants are totally targeting for heterogeneity and average energy available within the network, results in life time enhancement. There are some variants of LEACH and HEED offers better result compared to the original LEACH and HEED protocol in terms of adding node distance and heterogeneity of nodes. Other important parameter from the present literature is node degree, available energy on routing path, spanning tree basis and some of the Bio-inspired base like Bee colony and mechanical base of firefly-simulated annealing also add weightage to select best possible routing mechanism with clustering. PEGASIS basis of chain based data transaction is also used in intra-cluster communication and single hop or multihop communication can be used for $\mathrm{CH}$ to $\mathrm{BS}$ communication. According to some of the authors selected $\mathrm{CH}$ must be at center gives best node Connectivity, and better coverage results in best clustering. Hence results in more stability and prolonged lifetime of WSN. Researcher also target for distance between different $\mathrm{CH}$ positions, which also contribute in lifetime enhancement of the network. So, there is high need to design a clustering scheme which having the provision of identifying best possible cluster by keeping internal messages as low as possible other than valuable data message. If there is any death of node then there must be provision to trigger the cluster head and base station. Other option for the energy efficient clustering scheme is to check node available in cluster must have minimum energy for communication.

\section{CONCLUSION}

With the complete survey of reported literature here it is identified that most of the researchers still follow a random deployment strategy with modified probability weight function and with the threshold comparison decision is taken for cluster head. So there is high need to have intelligent scheme based on automata or neural network such that nodes clustering and head selection is executed based on real time or run time value.

Hence there is high need to design and develop clustering algorithm of Non-probabilistic approach type for balancing the clusters, and must result optimal number of cluster in the network such that network survival time get improved. Hence, indirectly stability of the network get enhances. If life of the network is extending, then it indirectly contributes for packet delivery ratio to BS and hence throughput enhances.

\section{ACKNOWLEDGMENT}

The author would like to thanks Prof. Dr. G.K.Kharate and Dr. V.H. Patil from Matoshri College of Engineering and Research Centre, for their continuous support for our research work and valuable suggestion and constructive comments to improve the quality of research work.

\section{REFERENCES}

[1] R. Sheikhpour, S. Jabbehdari and A. Khadem-Zadeh, "Comparison of energy efficient clustering protocols in Heterogeneous wireless sensor networks," International Journal of Advanced Science and Technology, November, 2011, pp. 27-40

[2] A. A. Abbasi and M. Younis, "A survey on clustering algorithms for wireless sensor networks," Science Direct Computer Communications, 2007, pp. 2826-2841

[3] S.Dehghani, M.Pourzaferani and B.Barekatain ,"Comparison on energy-efficient cluster based routing algorithms in Wireless Sensor Network," The Third Information Systems International Conference, Science Direct, Procedia Computer science, Vol.72,2015,pp.535542

[4] A.K.Tripathi and S.Chinara, "Comparison of Residual Energy-Based Clustering Algorithms for Wireless Sensor Network," International Scholarly Research Network Sensor Network, Vol.2012,pp.1-10,Doi:10.5402/2012/375026

[5] C.K.Sendhilkumar,R.Sukumar and M.Nageswari, " Sensors lifetime enhancement techniques in wireless sensor network," IRACSTInternational Journal of Computer Science and Information Technology and Security, April 2013, Vol.3 ,No.2,pp.159-164 
[6] W. R. Heinzelman, A. Chandrakasan, and H. Balakrishnan, "Energy-Efficient Communication Protocol for Wireless Microsensor Networks," In Proceedings of the 33rd Annual Hawaii International Conference on System Sciences, Maui, HI, USA, 4-7 January 2000 , pp. $10-19$

[7] M. J. Handy, M. Haase and D. Timmermann, “ Low Energy Adaptive Clustering Hierarchy with Deterministic Cluster-Head Selection," IEEE conference on mobile and wireless sensor networks, 2002, pp.368-372

[8] A.A.Kazerooni, H.Jelodar and J.Aramideh, "LEACH and HEED Clustering Algorithms in Wireless Sensor Networks: A Qualitative Study," Advances in Science and Technology: Research Journal, Vol.9,No.25,March 2015, pp.7-11, Doi:10.12913/22998624/1918

[9] S Jung., Y. Han and T. Chung, " The Concentric Clustering Scheme for Efficient Energy Consumption in the PEGASIS," In Proceedings of the 9th International Conference on Advanced Communication Technology, Gangwon-Do, Korea, 12-14 February 2007, pp. 260-265

[10] O. Younis and S. Fahmy, "HEED: A hybrid, energy-efficient, distributed clustering approach for ad-hoc sensor networks," IEEE Trans. Mobile Comput. 2004, pp. 366-379

[11] H. Kour and A. K. Sharma, "Hybrid Energy Efficient Distributed Protocol for Heterogeneous Wireless Sensor Network," International Journal of Computer Applications (0975-8887), July 2010, vol.4, No.6, pp.1-10

[12] A. Manjeshwar and D. P. Agrawal , "TEEN: A Routing Protocol for Enhanced Efficiency in Wireless Sensor Networks," In Proceedings of the 15th International Parallel and Distributed Processing Symposium (IPDPS), San Francisco, CA, USA, 23-27 April 2001, pp. 2009-2015

[13] A .Manjeshwar and D. P .Agrawal , "APTEEN: A Hybrid Protocol for Efficient Routing and Comprehensive Information Retrieval in Wireless Sensor Networks," In Proceedings of the 2nd International Workshop on Parallel and Distributed Computing Issues in Wireless Networks and Mobile computing, Lauderdale, FL, USA, 15-19 April 2002, pp. 195-202.

[14] Li Chengfa, Y. Mao, G. Chen and Wu, Jie, “ An Energy-Efficient Unequal Clustering Mechanism for Wireless Sensor Networks," In Proceedings of the 2nd IEEE International Conference on Mobile Ad-hoc and Sensor Systems Conference (MASS), Washington, DC, 7-10 November 2005, pp. 596-604

[15] G. Chen, Li Chengfa, Ye. Mao and Wu Jie , “An unequal cluster-based routing protocol in wireless sensor networks," Springer, Wireless Network, April 2007, pp.193-207

[16] J. YU, Y. QI and G. Wang, "An energy-driven unequal clustering protocol for heterogeneous wireless sensor networks," J Control Theory Appl.2011, pp.133-139

[17] G. Smaragdakis, I. Matta and A. Bestavros, "SEP: A Stable Election Protocol for clustered heterogeneous wireless sensor network," In Second International Workshop on Sensor and Adhoc Network Protocols and Applications, 2004,pp.1-6

[18] A. Kashaf, N. Javaid, Z. A. Khan and I. A. Khan, "TSEP: Threshold Sensitive Stable Election Protocol," CS-NI ar xiv 17, December 2012, pp.1-5

[19] J. Chang and P. Ju, "An efficient cluster-based power saving scheme for wireless sensor networks," Eurasip Journal on Wireless Communications and Networking a Springer Journal, 2012:172, pp.1-10, Doi:10.1186/ 1687-1499-2012-172

[20] G. Abdul-Salaam, A.H.Abdullah,M.H.Anisi,A.Gani and A.Alelaiwi,“ A Comparative analysis of energy conservation approaches in hybrid wireless sensor networks data collection protocols," Telecommunication Syst(2016),Vol.61, pp.159-179, Doi:10.1007/s11235015-0092-8

[21] O.Rehman, N.Javaid, B.Manzoor, A.Hafeez, A.Iqbal and M.Ishfaq, "Energy Consumption Rate Based Stable Election Protocol," International Workshop on Body Sensor Networks (BASNet-2013),SciVerse Science Direct, Procedia Computer science, Vol.19,2013,pp.932-937

[22] F. Farouk, R. Rizk, F. W. Zaki, "Multi-level stable and energy-efficient Clustering protocol in heterogeneous wireless sensor networks," IET Wireless Sens.Syst., 2014, pp. 159-169

[23] D.Kumar,T. C. Aseri and R.B. Patel, “EEHC: Energy efficient heterogeneous cluster scheme for wireless sensor networks," Elsevier computer communication,2009, pp.662-667

[24] L. Qing, Q. Zhu and M. Wang, "Design of a distributed energy-efficient clustering algorithm for heterogeneous wireless sensor network," ELSEVIER, Computer Communications, Vol.29, 2006; pp 2230- 2237

[25] B. Elbhiri, S.Rachid, S.E.Fkihi, S. and D. Aboutajdine, "Developed Distributed Energy- Efficient Clustering (DDEEC) for heterogeneous wireless sensor networks," 5th International Symposium on I/V Communications and Mobile Network (ISVC), 2010, pp. 1-4

[26] P. Saini and A. K. Sharma, “E-DEEC- Enhanced Distributed Energy Efficient Clustering Scheme for heterogeneous WSN," 1st International Conference on parallel, Distributed and Grid Computing (PDGC - 2010), pp. 205-210

[27] N Javaid, T.N.Qureshi, A.H.Khan A.Iqbal, E.Akhtar and M.Ishfaq , "EDDEEC: Enhanced Developed Distributed Energy-Efficient Clustering for Heterogeneous Wireless Sensor Networks," International workshop on body area sensor networks (BASNet -2013), 2013, pp.914-919

[28] N. Javaid, M. Babar Muhammad, Imran, M.Guizani, Z. Ali Khan, T.A. Alghamadi and M.Llahi, "An energy-efficient distributed clustering algorithm for heterogeneous WSNs," EURASIP Journal on Wireless Communications and Networking, Springer 2015, pp.3-11

[29] T.N.Qureshi,N.Javaid,A.H.Khan,A.Iqbal,E.Akhtar, M.Ishfaq, "BEENISH: Balanced Energy Efficient Network Integrated Super Heterogeneous Protocol for Wireless Sensor Networks," International Workshop on Body Area Sensor Networks(BASNet2013),SciVerse Science Direct, 2013, Vol.19,pp.920-925

[30] M.Y.Khan, N.Javaid, M.A.Khan, A.Javaid, Z.A.Khan and U.Qasim, "HYBRID DEEC: Towards Efficient Energy Utilization in Wireless Sensor Networks," World Applied Sciences Journal,2013, pp.126-132

[31] B.Elbhiri,R.Saadane,D.Aboutajdine, "Stochastic Distributed Energy Efficient Clustering (SDEEC) for heterogeneous wireless sensor networks," IGST-CNIR Journal, December 2009, Vol.9, Issue 2, pp.11-17

[32] B.Elbiri, R. Saadane, A. Zamora, D. Aboutajdine "Stochastic and Balanced Distributed Energy- Efficient Clustering (SBDEEC) for heterogeneous wireless sensor networks," Infocom Journal of Computer Science, 2009, Vol.8, No.3, pp.11-20

[33] D. Mantri,N.R. Prasad and R. Prasad, "MHBCDA: Mobility and Heterogeneity aware Bandwidth Efficient Cluster based Data aggregation for Wireless Sensor Network,"IEEE Conference 2013, pp.1-5

[34] Ye M.,Li C., Chen G.and Wu, J., "EECS: An Energy Efficient Clustering Scheme in Wireless Sensor Networks," In Proceedings of the 24th IEEE International Performance, Computing, and Communications Conference (IPCCC), Phoenix, AZ, USA, 7-9, April 2005, pp.535-540

[35] P.Saini and A.K.Sharma,"Energy Efficient Scheme for Clustering Protocol Prolonging the Lifetime of Heterogeneous Wireless Sensor Networks," International Journal of Computer Applications (0975 - 8887), September 2010, Vol.6, No.2,pp.30-36

[36] M. Diwakar and S. Kumar , "An Energy Efficient Level Based Clustering Routing Protocol for Wireless Sensor Networks," International Journal of Advanced Smart Sensor Network System (IJASSN),April-2012, pp.55-65 
[37] S. Kumar,M. Prateek and B. Bhushan , "Energy Efficient (EECP) Clustered Protocol for Heterogeneous Wireless Sensor Network," International Journal of Advance Research in computer Science and Software Engineering, July-2013, pp.1448-1453

[38] S. A.Nikolidakis, D. Kandris, Dimitrios D.Vergados and C. Douligeris, "Energy Efficient Routing in Wireless Sensor Networks Through Balanced Clustering," Algorithms-2013, pp.29-42

[39] D.P.Dahini,V.P.Singh and C.K.Ho " "Topology-controlled adaptive clustering for uniformity and increased lifetime in wireless sensor networks," IET Wireless Sensor System, 2012, pp.318-327

[40] G.Raval, M.Bhavsar and N.Patel "“Analyzing the Performance of Centralized Clustering Techniques for Realistic Wireless Sensor Network Topologies," Third International Conference on Recent Trends in Computing 2015 (ICRTC-2015), Science Direct, Procedia Computer science, Vol.57,2015,pp.1026-35

[41] C.Wen and W.A.Sethares, “Automatic Decentralized Clustering for Wireless Sensor Networks,” Eurasip Journal on Wireless Communications and Networking, 2005, Vol.5,pp.686-697

[42] S.Dutt and O.S.Khanna, "An Enhanced Energy Efficient Clustering Scheme for Prolonging the Lifetime of Heterogeneous Wireless Sensor Networks," International Journal of Computer Applications (0975-8887), Vol.76, August 2013,pp.27-32

[43] M.N.Brazil,C.J.Ras and D.A.Thomas,"Relay Augmentation for Lifetime Extension of Wireless Sensor Networks," IET Wireless Sensor Systems 2013, Vol.3,Issue.2,pp.145-152,Doi:10.1049/iet-wss.2012.0126

[44] S.Ganesh and R.Amutha,"Efficient and Secure Routing Protocol for Wireless Sensor Networks through SNR Based Dynamic Clustering Mechanisms," Journal of communications and Networks, Vol.15.No.4,August 2013,pp.422-429

[45] Y.Yao, Q.Cao and A.V.Vasilakos, "EDAL:An Energy-Efficient, Delay-Aware, and Lifetime-Balancing Data Collection Protocol for Heterogeneous Wireless Sensor Networks," IEEE/ACM Journal on Networking, Vol.23, No.3, June 2015,pp.810-823

[46] Z.Hong, R.Wang and X. Li, "A Clustering-tree Topology Control Based on the Energy Forecast for Heterogeneous Wireless Sensor Networks," IEEE/CAA Journal of Automatica Sinica, Vol.3, No.1,January 2016,pp.68-77

[47] S.Bhatti,J.Xu and M.Memon , "Clustering and fault tolerance for target tracking using wireless sensor networks," IET Wirel.Sens.Sys.,2011, pp.66-73

[48] V.Pal, Yogita, G. Singh and R.P.Yadav, "Effect of Heterogeneous Nodes Location on the Performance of Clustering Algorithms for Wireless Sensor Networks," Third International Conference on Recent Trends in Computing 2015 (ICRTC-2015), Science Direct, Procedia Computer science, Vol.57,2015,pp.1042-1048

[49] D.P.Nudurupati and R.K.Singh "Enhancing Coverage Ratio using Mobility in Heterogeneous Wireless Sensor Network ," International Conference on Computational Intelligenec:Modeling Techniques and Applications (CIMTA-2013), Science Direct, Procedia Technology, Vol.10, 2013, pp.538-545

[50] H.Tan, X. Hao, Y.Wang, F.C.M.Lau and Y.Lv,"An Approximate Approach for Area Coverage in Wireless Sensor Networks,” The 4th International Conference on Ambient Systems, Networks and Technologies (ANT-2013), SciVerse Science Direct, Procedia Computer science, Vol.19, 2013, pp.240-247

[51] A.S.Poornima and B.B.Amberker, "Secured Data Collection Using Mobile Data Collector Clustered Wireless Sensor Networks," IET Wireless Sensor Systems, 2011,Vol.1,Issue.2,pp.85-95,Doi:10.1049/iet-wss.2010.0086

[52] F.boutekkouk, F. Taibi and K. Meziani, "A hybrid approach to extend the lifetime of heterogeneous wireless sensor networks," The 6th International Conference on Emerging Ubiquitous System and Pervasive Networks (EUSPN 2015), Procedia Computer Science (2015), Vol.63, pp.136-141

[53] S.Hu, J.Han and X.Wei and Z.Chen,“ A Multi-hop heterogeneous cluster-based optimization algorithm for wireless sensor networks,"Wireless Netw(2015),Vol.21,pp.57-65,Doi:10:1007/s11276-014-05769-z

[54] N.Dimokas, D.Katsaros and Y.Manolopoulos, "Energy-efficient distributed clustering in wireless sensor networks," Journal of Parallel and Distributed Computing, Vol.70, 2010, pp.371-383, Doi: 10.1016/ j.jpdc. 2009.08.007

[55] K.Rana and M.Zaveri,"Synthesized cluster head selection and routing for two tier wireless sensor network," Hindwai Publishing corporation: Journal of computer network and communications,Vol. 2013, Article ID 578241,11 Pages

[56] M.Yi Wang, J.Ding, W.Chen and W.Guan, "SEARCH:A Stochastic Election Approach for Heterogeneous Wireless Sensor Networks," IEEE Communications letters, March 2015,Vol.19,No.3,pp.443-446

[57] G. S. Arumugam and T. Ponnuchamy, "EE-LEACH: development of energy-efficient LEACH Protocol for data gathering in WSN," EURASIP Journal on Wireless Communications and Networking (Springer), Springer-2015,pp.1-9

[58] B.Manzoor, N.Javaid, O.Rehman, M.Akbar, Q.Nadeem, A.Iqbal, and M.Ishafaq ,"Q-LEACH: A New Routing Protocol for WSNs," International Workshop on Body Area Sensor Networks(BASNet-2013), SciVerse ScieceDirect,Vol.19, pp. 926-931

[59] D. Zhang, X. Wang, X.T. Zhang and Y. Zhu, "A new clustering routing method based on PECE for WSN, " EURASIP Journal on Wireless Communications and Networking, Springer-2015,pp.1-13

[60] N. G. Praveena and H. Prabha, "An efficient multi-level clustering approach for a heterogeneous wireless sensor network using link correlation," EURASIP Journal on Wireless Communications and Networking, Springer 2014,pp.1-10

[61] N.Javaid,M.Aslam,A.Ahmad,Z.A.Khan,T.A.Alghamdi, "MCEEC: Multi-hop Centralized Energy Efficient Clustering Routing Protocol for WSNs, " IEEE ICC 2014-Communications Software, Services and Multimedia Applications Symposium,pp.1784-89

[62] Y.Li, G.Xiao,G.Singh and R.Gupta, "Algorithms for finding best location of cluster heads for minimizing energy consumption in wireless sensor network," Wireless Netw(2013),Spinger-2013, pp.1755-1768, Doi:10:1007/s11276-013-0566-0

[63] C. Gherbi,Z. Aliouat and M.Benmohmmed, "A Load -Balancing and self-adaption clustering for lifetime prolonging in large scale wireless sensor networks," The International Conference on Advanced Wireless, Information, and Communication Technologies (AWICT 2015), Science Direct (2015), Vol.73,pp.66-75

[64] J. Liu and Y.Hu, "A Balanced and Energy Efficient Clustering Algorithm, for Heterogeneous Wireless Sensor Networks," Sixth International Conference on Wireless Communication and Signal Processing (WCSP), 2014, pp:1-6

[65] H. Li, J. Liu, "Double Cluster Based Energy Efficient Routing Protocol for Wireless Sensor Network," Springer, Int. J. Wireless Inf. Networks, 2016, Vol. 23, pp.40-48

[66] S. Singh, A.Malik and R. Kumar, " Energy efficient heterogeneous DEEC protocol for enhancing lifetime in WSNs," Engineering Science and Technology an International Journal xxx(2016), pp:1-9

[67] N.R.Wankhede, D.N Choudhari, "Novel Energy Efficient Election Based Routing Algorithm for Wireless Sensor Network," 7th International Conference on Communication, Computing and Virtualization 2016,Procedia Computer Science (2016), Vol.79, pp.772780

[68] H.S.Jangwan and A. Negi, "Enhanced Energy-Efficient Balanced Clustering Protocol for WSN," International Journal of Applied Engineering Research (2016), Vol.11, No.5, pp:3619-3623

[69] S.Zairi, B.Zouari, E.Niel and E.Dumitrescu," Nodes Self-Scheduling approach for maximizing wireless sensor network lifetime based on remaining energy,” IET Wireless Sensor Systems, Vol.2, issue.1, 2012,pp.52-62 
[70] M. Arioua, Y. el Assari, I. Ezzazi and A. el Qualkadi, "Multi-hop cluster based routing approach for wireless sensor network," The 7th International Conference on Ambient Systems, Networks and Technologies (ANT 2016),Procedia Computer Science (2016), Vol. 83, pp.584-591

[71] A.Sarkar and T. S. Murugan, "Routing Protocols for wireless sensor networks: What the literature says?," Alexandria Engineering Journal, 2016, pp.1-11

[72] I.Butun, I.Ra and R. Sankar, "PCAC:Power- and Connectivity-Aware Clustering for Wireless Sensor Networks," Springer: EURASIP Journal on Wireless Communication and Networking, 2015, Vol:83, pp.1-15

[73] A. Azimi, S. Kashani, A. Mohamad and M. Noori, "EEULA:An Energy-Aware Event-Driven Unicast Algorithm for Wireless Sensor Network by Learning Automata," Research Journal: Advances in Science and Technology (June 2016), Vol:10, pp.9-18

[74] S.Chand, S.Singh and B. Kumar, "Heterogeneous HEED Protocol for Wireless Sensor Networks," Springer: Wireless Pers. Commun, 2014, Vol.77, pp.2117-2139

[75] J.Singh,R.N.Gupta,N.Sharma,"Energy Efficient Data Communication Approach In Wireless Sensor Network," International Journal of Advanced Smart Network Systems (IJASSN), July 2014, Vol. 4, No.3, PP.1-12

[76] M. Bsoul, A. Al-Khasawneh, A. E. Abdallah, E. E. Abdallah and I. Obeidat, "An Energy-Efficient Threshold-Based Clustering Protocol for Wireless Sensor Networks," Wireless Pers. Commun., 2013, Vol. 70 , pp. 99-112,DOI 10.1007/s11277-012-0681-8

[77] M. Faheem, M. Z. Abbas, G.Tuna, V.C.Gungor,"EDHRP: Energy efficient event driven hybrid routing protocol for densely deployed wireless sensor networks," Journal of Network and Computer Applications, 2015, Vol. 58, pp.309-326

\section{AUTHOR PROFILE}

Santosh Vishnu Purkar received the B.E (Electronics engineering) from S.S.V.P.S.College of engineering Dhule (North Maharashtra University) and M.Tech. (Electronics and Telecommunication) from V.J.T.I, Mumbai in Maharashtra (India) in 1998 and 2009, respectively. He is currently pursuing Ph.D. under the guidence of Dr. R.S.Deshpande at M.C.O.E.R C., Nashik Eklahare, Odha. His research interest includes Wireless Sensor Network, Wireless Communication and Computer Networks.

R.S.Deshpande is currently working as Principal at Shri. Chhatrapati Shivaji Maharaj College of Engineering Nepti, Ahmednagar (M.S). His areas of research are ATM System, Wireless and adhoc networks and signal processing. He contributes for different national and international journals. He received his Ph.D. from Rajiv Gandhi Technological University on the topic "ATM Congestion Control Mechanisms" in the year 2009. He is renowned academician and having an experience of more than 25 years. 